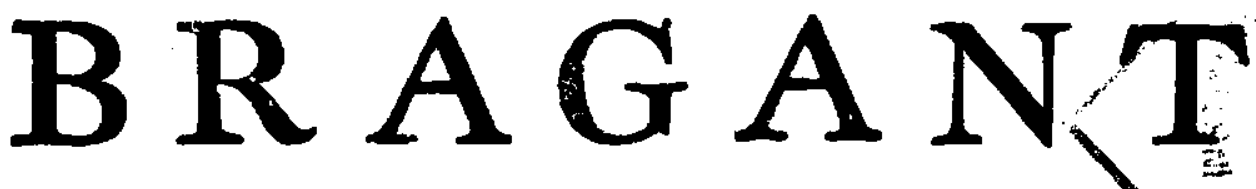

Boletim Técnico da Divisão de Experimentasão ${ }_{e}$ INSTITUTO AGRONÔMICO

Vol. 7

Campinas, Maio de 1947

$\mathrm{N} \cdot{ }^{\circ} 5$

\title{
ESTUDO PRELIMINAR DO SISTEMA ÁGUA-SOLO-PLANTA NO ESTADO DE SÃO PAULO
}

J. E. de Paiva Neto

e

W. De Jorge

Este pequeno trabalho tem dois objetivos : o primeiro é apresentar alguns resultados obtidos em laboratório, a respeito do sistema água-solo-planta no Estado de São Paulo; o segundo é fornecer os processos de determinação dos dados físicos, referentes ao sistema água-solo-planta, que são utilizados nos laboratórios de física do solo, da Secção de Agrogeologia do Instituto Agronômico de Campinas.

\section{CONVENÇÕES E FATÔRES}

1) T F S A, significa terra fina sêca ao ar.

2) Estufa, subentende-se sempre em faixa térmica $105^{\circ}-110^{\circ} \mathrm{C}$.

3) T F SE, é terra fina sêca na estufa até constância de pêso.

Trabalhamos com pêso de T F S A, e referimos os dados físicos obtidos, a pêso de TFSE, ou a volume de solo ao natural, assim:

4) \% pêso, significa percentagem relativa a pêso de TFSE.

5) \% volume, vem a ser percentagem relativa a volume de solo ao natural.

Os fatôres usados são :

6) f, fator pêso, pelo qual multiplicamos os dados físicos obtidos percentualmente em pêso de T F SA, para referí-los a \% pêso.

$$
\mathrm{f}=\frac{100}{100-W}
$$




\section{Cálculo de W: (Umidade higroscópica)} T F S E :

Levamos 20 gramas de T F S A à estufa e obtemos (20-d) gramas de $\mathrm{W} \%$ em pêso de $\mathrm{T} F \mathrm{SA}=5 . \mathrm{d}$

7) $\mathrm{f}^{\prime}$, fator volume, pelo qual multiplicamos os dados físicos obtidos percentualmente em pêso de T F SA, para referí-los a $\%$ volume.

$$
f^{\prime}=f \cdot s^{\prime}
$$

Cálculo de $\mathbf{s}^{\prime}$ : (massa específica aparente)

Levamos $100 \mathrm{~cm}^{3}$ de solo ao natural à estufa e obtemos $\mathrm{x}$ gramas de solo sêco.

$$
\mathrm{s}^{\prime}=\frac{\mathrm{x}}{100}
$$

\section{PRIMEIRAS CONSIDERAÇÕES}

Quando do estudo do sistema água-solo-planta, feito num laboratório de física do solo cuja finalidade precípua é o levantamento de dados de importância prática, que irão constituir um requisito prévio de aprovação de um projeto de irrigação, drenagem, etc., aceitamos que o solo (ou sua terra fina) quando sêco na estufa não contém água.

As nossas observaçóes e pesquisas sôbre o sistema água-solo-planta têm como guia fundamental a Umidade de murchamento. Este dado foi sugerido por Briggs e Shantz (4) e vem a ser a umidade que conserva o solo quando ocorre e se mantém o murchamento da planta.

Adiante mostraremos que a Umidade de murchamento (símbolo U.mu.) está em intima correlação com a Umidade equivalente, valendo aquela 0,68 desta, para os solos do Estado de São Paulo.

Consideremos um solo (ou sua terra fina) sêco na estufa. Vamos umidecêlo aos poucos, fazendo notar que, a determinados teores de água no solo, correspondem denominações especiais. Estes teores de umidade são de interêsse teórico e prático.

Começamos levando v.g. 20 gramas de T F S A à estufa e obtemos (20-d) gramas de T F S E. A percentagem de água que contém a T F S A chama-se Umidade higroscópica (símbolo W).

W varia com o solo, com a temperatura e com a umidade relativa do ar. Este dado faz parte do fator pêso e aí está sua grande importância. A umidade higroscópica é função não decrescente da área especifica do solo ; a constituição química dêste influi também naquela, razão pela qual nos parece uma emprêsa altamente temerária tentar uma expressão analítica para a referida função.

Levemos agora os 20 gramas de T F S A a um dessecador, no qual a umidade relativa seja $96,4 \%$ aproximadamente (o que se consegue com uma solução de $\mathrm{H}_{2} \mathrm{SO}_{4} 1,49 \mathrm{~N}$ ), a terra ganha mais umidade até equilibrarse com a do ambiente. Segundo Mitscherlich (9), com $\mathrm{H}_{2} \mathrm{SO}_{4} 10 \%$ consegue- 
se um ambiente no qual o solo absorve umidade até anular-se o seu calor de umedecimento. Vageler, quando dirigia a Secção de Solos do Instituto Agronômico de Campinas, aconselhava uma solução a $7,3 \%$ de $\mathbf{H}_{2} \mathrm{SO}_{4}$ de acôrdo com Walter (13) para obter 50 atmosferas de pressão osmótica, considerando que a maioria das plantas cultivadas não têm fôrça de sucção superior a 50 at. Determinamos a higroscopicidade do solo com ácido sulfúrico $1,49 \mathrm{~N}$. Essas modificações não têm importância a nosso ver desde que se faça sempre do mesmo modo. Keen (8) pondera a nosso favor... "the hygroscopic coefficient has no real existence, and that even if it had, the experimental measurement would be impracticable". Consideramos convencional qualquer fixação de umidade ambiente para determinação da higroscopicidade do solo e definímo-la como sendo a percentagem de água que o solo é capaz de absorver, quando colocado num dessecador contendo no fundo $200 \mathrm{~cm}^{3}$ de $\mathrm{H}_{2} \mathrm{SO}_{4} 1,49 \mathrm{~N}$.

A higroscopicidade do solo (símbolo $\mathrm{Hy}$ ) é função não decrescente da área específica do solo e varia também com a sua constituição química. Os solos arenosos, sôltos, permeáveis, têm baixo $\mathrm{Hy}$; o contrário acontece com os solos argilosos, compactos, impermeáveis. As tabelas 3, 4 e 5 discutem outros pontos importantes sôbre a higroscopicidade.

Para os solos do Estado temos sempre $\mathrm{Hy}<$ U.mu. e como é sempre $\mathrm{W}<\mathrm{Hy}$ escrevenos :

$$
\mathrm{W} \subset \mathrm{Hy} \subset \mathrm{U} . \mathrm{mu} \text {. }
$$

$\mathrm{O}$ sinal $\subset$ deve ser lido, está contido, e, quando usarmos $\supset$ deve ser lido, contém.

Com esta notação matemática queremos deixar bem claro que :

a) a umidade higroscópica (W) e a higroscopicidade (Hy) são teores de umidade que as plantas em geral não utilizam.

b) atribuimos a uma só categoria de fôrças (as fôrças capilares) a retenção de água pelo solo.

Passemos a outro dado, introduzido por Briggs e Mc Lane (2, 3), a Umidade equivalente (símbolo U. Eq.) ou água equivalente (moisture equivalent). Este dado é a percentagem de água que conserva o solo (prèviamente saturado com água) quando sujeito a uma aceleração centrífuga igual a 1000 gravidades.

Obtivemos sempre :

$$
\text { U.Eq. } \supset \text { U.mu. } \supset \mathrm{Hy} . \supset \mathrm{W} \text {. }
$$

O processo original da determinação da U.Eq. $(2,3)$ foi modificado por nós em alguns detalhes, mas as diferenças que se obtêm empregando com rigor o processo original são insignificantes.

A tabela 1 mostra a íntima correlação que há entre a Umidade equivalente $\mathrm{e}$ a Umidade de murchamento :

$$
\text { U.mu. } \%=0,68 \text { U.Eq. } \%
$$

Partimos da T F S E e vimos acrescentando água aos poucos, obtendo W, Hy, U.mu. e U.Eq. 
Obtemos também outro dado, a água capilar máxima (símbolo A), quantidade máxima de água que um solo pode reter. Temos sempre A つ.U.Eq., logo,

$$
\text { A } \supset \text { U.Eq. } \supset \text { U.mu. } \supset \text { Hy. } \supset \text { W. }
$$

Concluimos que o máximo de água que um solo pode reter é $\mathrm{A}$, e o mínimo é $\mathrm{W}$.

Ao determinarmos a água capilar máxima de um solo, obtemos simultâneamente outros dados, que podem orientar as práticas de irrigação e drenagem :

1) ascensão capilar máxima, $\mathrm{h}_{\mathbf{T}}$, dada em milímetros ; é a maior distância que a água pode vencer num dado solo;

2) velocidade máxima de ascensão capilar, $V_{\mathbf{h}}$, dada em $\mathrm{mm} / \mathrm{hora}$; é maior velocidade que pode ter a água no solo;

3) altura máxima de água absorvida, $\mathbf{H}_{\mathbf{T}}$, dada em milímetros ; é a altura da camada de água capaz de ser absorvida pelo solo;

4) velocidade máxima de absorção, $\mathrm{V}_{\mathrm{H}}$, dada $\mathrm{em} \mathrm{mm} / \mathrm{hora}$; é a maior velocidade com que a água pode ser absorvida pelo solo.

Antes de expor os processos de determinação dos dados a que já nos referimos, faremos algumas considerações sôbre a equação $y=\frac{x T}{x+q T}$.

Quando na" natureza um processo caminha para um valor final, êle segue,_segundo_Vageler $(5,10)$, a equação citada.

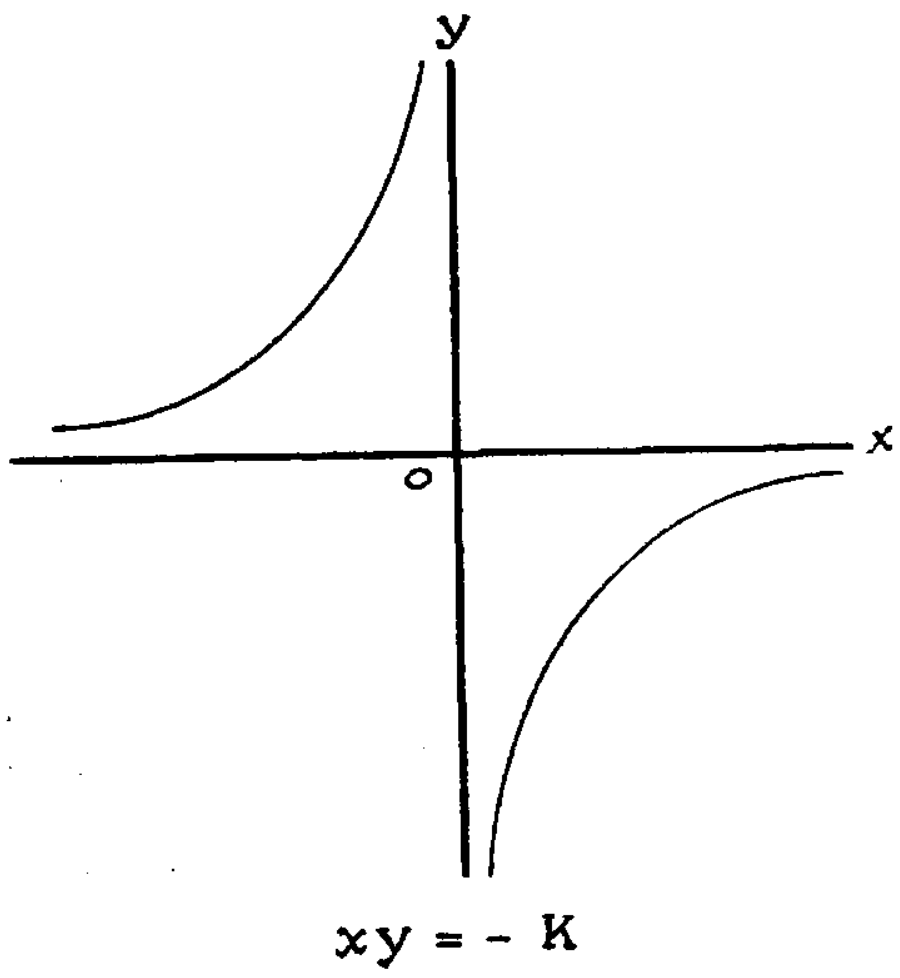

fig. 1

O uso desta equação especialmente no estudo da adsorção pela fração coloidal do solo é feito desde 1859 por Th. G. O. Wolff segundo Albareda (I).
1) A equação $y=\frac{x T}{x+q T}$ resulta da seguinte $x^{2}-y^{2}=a^{2}$ que é a equação da hipérbole equilátera, na qual se faz uma rotação e uma translação conveniente de eixos, procurando uma curva teórica que mais se aproxime da curva gráfica obtida com os dados experimentais.

Faz-se uma rotação de $45^{\circ}$ obtendo a hipérbole equilátera referida às assintotas :

$$
x y=-a^{2}
$$

Fazendo $a^{2}=K$ (constante) teremos $x y=-K$. (fig. 1). 
Como os fenômenos a serem estudados caminham para um valor final v.g. T, é preciso, para adaptar a curva ao fenômeno, fazer uma translação de eixos que forneça $o$ valor $\mathrm{T}$ para $\mathrm{y}$, quando $\mathrm{x}$ tender ao infinito.

Basta (figs. 2 e 3) fazer uma translação de eixos para a nova origem $\mathrm{O}^{\prime}(\mathrm{x} \mathrm{q} \mathrm{T},-\mathrm{T})$. Feita ela, teremos :

$$
(\mathrm{x}+\mathrm{q} \mathrm{T}) \quad(\mathrm{y}-\mathrm{T})=-\mathrm{K}
$$

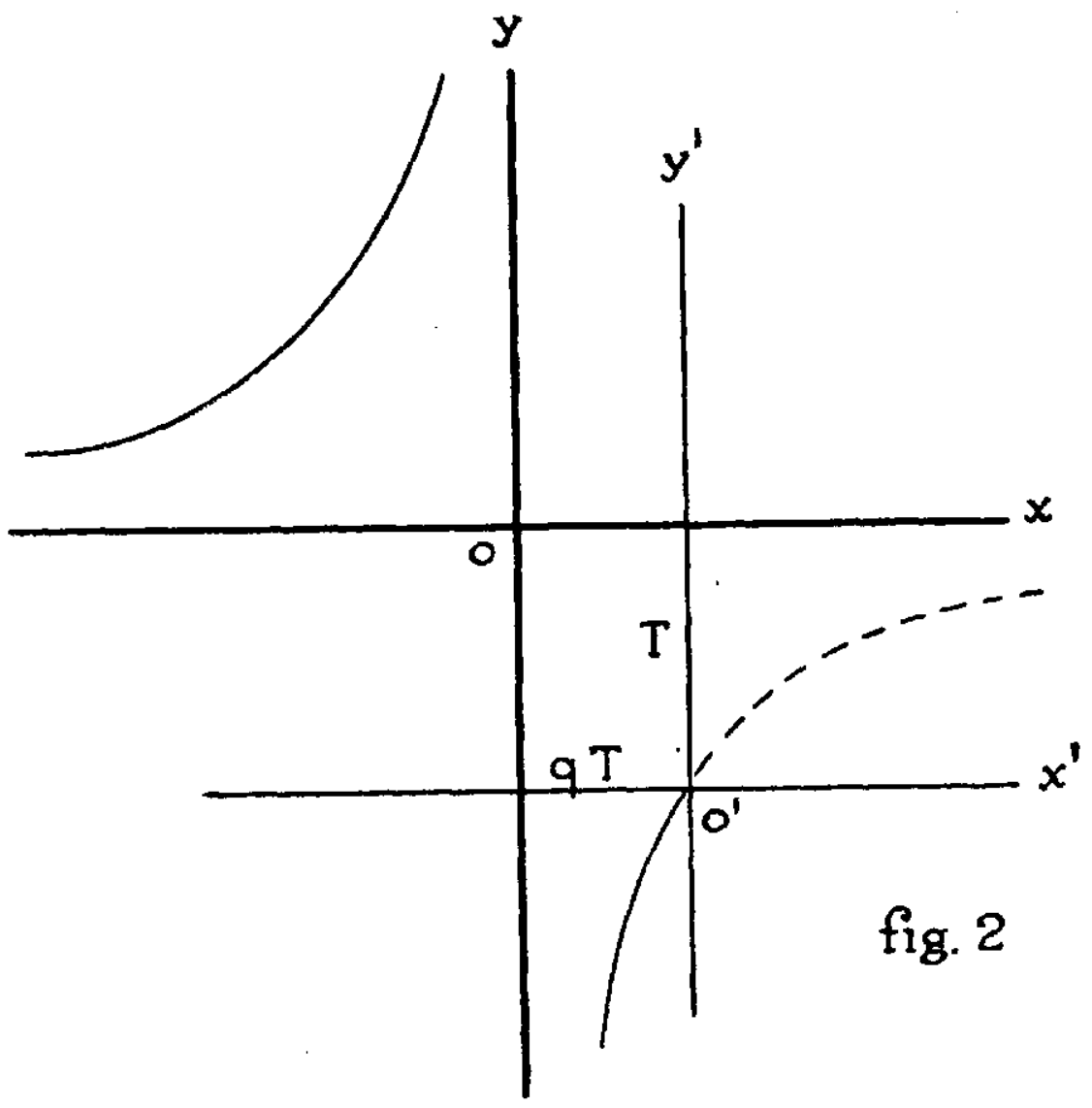

Como $x y=-K$, vemos, (fig. 2) que $x y=-K=-q^{2}$ e temos, finalmente,

$$
y=\frac{x T}{x+q T}
$$

Só nos interessam valores de $\mathrm{x}$ não negativos, razão pela qual, quando falarmos curva, fica subentendido que nos referimos sòmente à porção interrompida do ramo inferior da curva em sentido lato (fig. 2).

2) Para fixar as idéias, seja o caso da ascensão capilar. Quando do estudo dêste fenômeno, toma-se nota da ascensão em tempos diferentes. No eixo real representamos os tempos, e no eixo imaginário as respectivas ascensões. Temos neste caso :

$$
y=\frac{x T}{x+q T}=f(x) \text { onde, }
$$


a) $\mathrm{x}$ é o tempo ;

b) y é a ascensão ;

c) $\mathrm{T}$ é o valor final da ascensão, pois, $\lim \mathrm{f}(\mathrm{x})=\mathrm{T}$;

d) $\frac{1}{q}$ é a velocidade máxima de ascensão capilar, puis,

$\left[\frac{d}{d x} f(x)\right]_{x=0}=\frac{1}{q}$

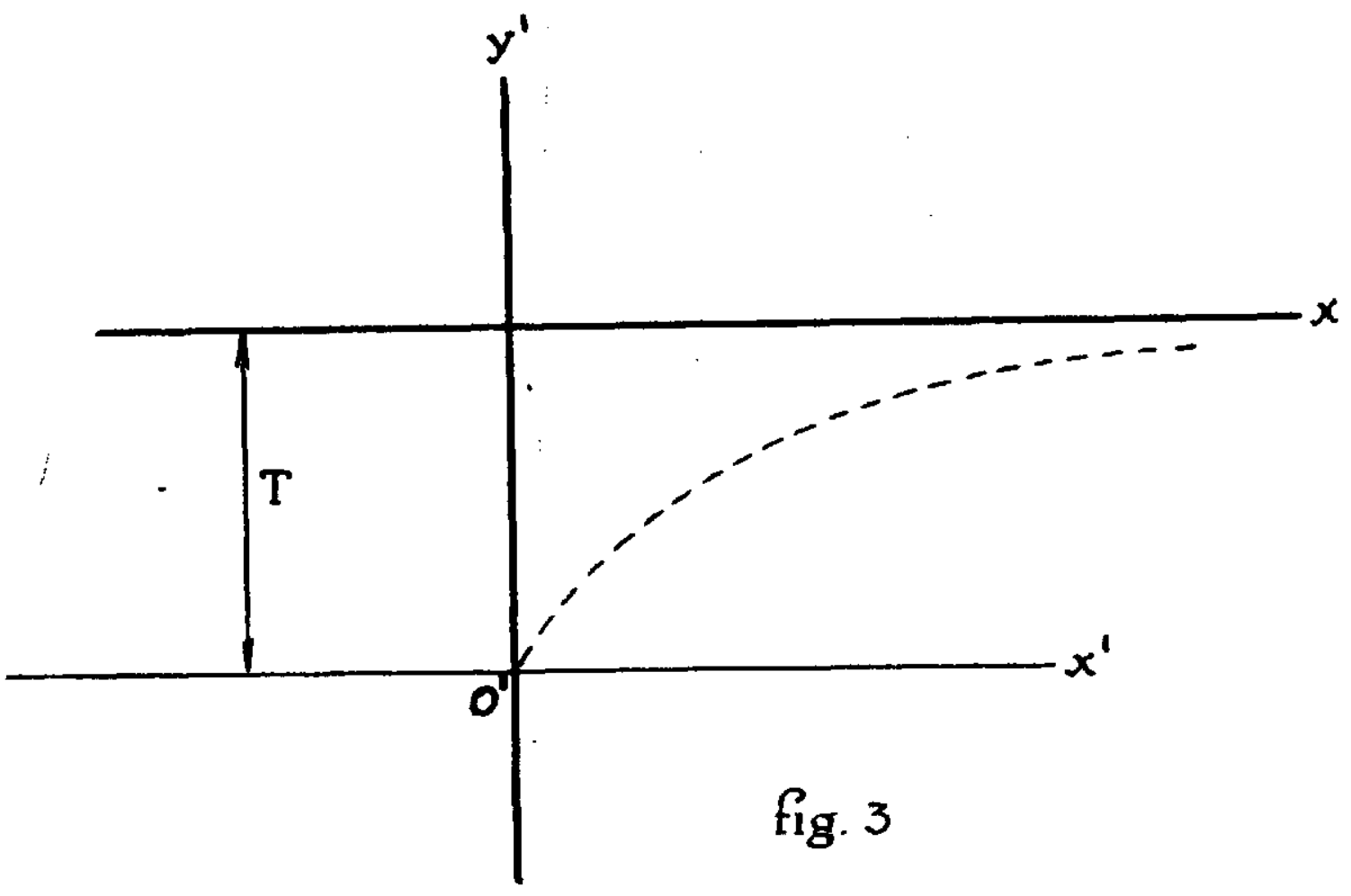

A fig. 4 mostra que o valor final é função direta da velocidade máxima de ascensão capilar.

3) E importante calcular $T$ (o valor final v. g. da ascensão capilar) mediante duas leituras feitas, e, também mediante as mesmas duas leituras, a valiar $\frac{1}{q}$ (velocidade máxima da ascensão capilar v. g.).

Sejam duas leituras $y_{1}$ e $y_{2}$, a primeira no fim de 1 dia, $\left(x_{1}=1\right)$ e a segunda após 5 dias, $\left(\mathrm{x}_{2}=5\right)$.

$$
\begin{aligned}
T & =\frac{4 y_{1} y_{2}}{5 y_{1}-y_{2}} \\
\frac{1}{q} & =\frac{4 y_{1} y_{2}}{\tilde{3}\left(y_{2}-y_{1}\right)}
\end{aligned}
$$




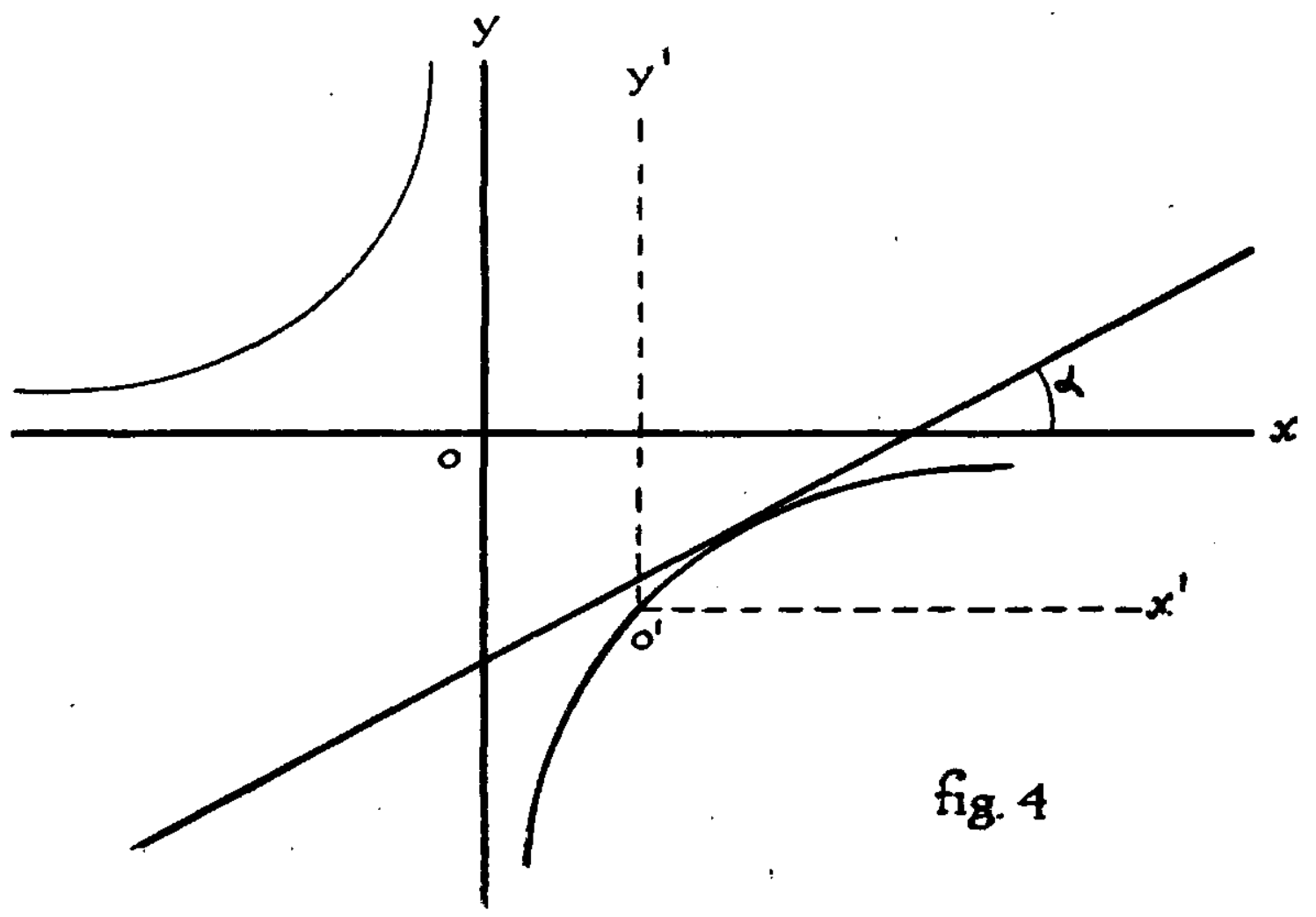

Supondo a ascensão capilar medida em milímetros, teremos acima a ascensão final em milímetros e a velocidade máxima em $\mathrm{mm} /$ dia. Para termos a velocidade máxima em $\mathrm{mm} /$ hora dividimos por 24 , e vem,

$$
\frac{1}{\mathrm{q}}=\frac{\mathrm{y} 1 \mathrm{y} 2}{30\left(\mathrm{y}^{2}-\mathrm{y} 1\right)} \text {. }
$$

No estudo da higroscopicidade, as observações devem ser feitas em intervalos de tempo mais longos. Podemos usar v.g., 5 e 10 dias. Teremos neste caso :

$$
\mathrm{T}=\frac{\mathrm{y} 1 \mathrm{y} 2}{2 \mathrm{y} 1-\mathrm{y}^{2}} \quad \frac{1}{\mathrm{q}}=\frac{\mathrm{y} 1 \mathrm{y} 2}{10\left(\mathrm{y}^{2}-\mathrm{y}^{1}\right)} .
$$

\section{PROCESSOS DE DETERMINAÇÃO DOS DADOS}

\section{I - W (umidade higroscópica)}

1 - Tomamos 20 g de T F S A numa caixa de Petri tarada;

2 - levámo-la à estufa e obtemos $(20$ - d) g de T F S E ;

3 - resfriámo-la num dessecador e pesamos.

5. $\mathrm{d}=\mathrm{W} \%$ em pêso de T F S A.

\section{II - Hy (higroscopicidade)}

$$
\begin{aligned}
& 1 \text { - Como em I }-1 \text {; } \\
& 2 \text { - como em I }-2 \text {; }
\end{aligned}
$$


3 - como em I - 3;

4 - expomos num dessecador contendo $\mathrm{H}_{2} \mathrm{SO}, 1,49 \mathrm{~N}$;

5 - pesamos nos dias 5 e 10 de exposição registando os aumentos de pêso yl e y2 ;

6 - obtemos $\mathrm{Hy} \%$ em pêso de T F S A $=\frac{5 \text { y1 y2 }}{2 \text { y1- } \mathrm{y}^{2}}$;

7 - mediante os fatôres obteremos $\mathrm{Hy} \%$ pêso e $\mathbf{H y ~} \%$ volume. III - U.mu. (umidade de murchamento)

Este dado é calculado: U.mu. $\%=0,68$ U.Eq. $\%$.

A tabela 1 fornece os dados iniciais comparativos com os quais estabelecemos a referida relação.

IV - U.Eq. (umidade equivalente) .

1 - Tomamos dois gramas de T F S ;

2 - êstes dois gramas vão a um cadinho perfurado (de Gooch) formando um pequeno tronco de cone invertido com aproximadamente $1 \mathrm{~cm}$ de altura;

3 - saturamos a terra por capilaridade até espelhar a superfície ;

4 - deixámo-la 30 minutos em câmara úmida para perder o excesso de água;

5 - centrifugámo-la a 1000 gravidades durante 30 minutos;

6 - pesámo-la ;

7 - levámo-la à estufa para obter T F SE;

8 - pesámo-la ;

9 - obtida a diferença $\mathbf{d}$ entre as duas pesagens, temos :

U. Eq. $\%$ em pêso de T F SA $=50 \mathrm{~d}$

V - A (água capilar máxima)

$\mathrm{Na}$ sua determinação obteremos simultâneamente outros dados sôbre os quais já nos referimos. Trabalhamos com tubos de vidro especial conhecidos por tubos de bomba, com $100 \mathrm{~cm}$ de comprimento e $1 \mathrm{~cm}$ de raio.

A balança usada por nós é sensível a um grama.

1 - Fechamos com gaze uma extremidade do tubo ;

2 - taramos o conjunto, tubo com a gaze;

3 - enchemos o tubo com T F S A até v. g. $90 \mathrm{~cm}$;

4 - pesamos o conjunto, tubo com a gaze e T F S A ;

5 - pomos para embebição marcando dia e hora;

6 - 24 horas depois, pesamos e medimos em milímetros a ascensão alcançada ;

$7-120$ horas depois, como em 6.

Nota. - Acontece muito raramente a ascensão alcançar em 120 horas os $90 \mathrm{~cm}$ de T F A usados; é preciso neste caso repetir a experiência fazendo as duas leituras em intervalos de tempo mais curtos. 


\section{DADOS ANALITICOS OBTIDOS}

Sejam :

t - tara do tubo fechado com gaze;

$\mathbf{P}$ - pêso do tubo fechado com gaze e com TF A até $90 \mathrm{~cm}$;

pè- pêso de T F S A usada $=\mathrm{P}-\mathrm{t}$.

Teremos :

1 - umidade da TFSA do tubo $=\frac{n W}{100} ;$

2 - gramas de T F S E no tubo $=\mathrm{p}\left(1-\frac{\mathrm{W}}{1 \mathrm{UO}}\right) ;$

3 - massa especifica aparente $s^{\prime \prime}$, da T F A do tubo,

$$
s^{\prime \prime}=\frac{p}{\pi 90}\left(1-\frac{W}{100}\right)
$$

4 - pêso $\mathrm{P}_{24}$, em 24 horas,

$\mathrm{P}_{24}=\mathrm{t}+\mathrm{p}+$ pêso de água absorvida em 24 horas ;

5 - ascensão $h_{24}$, em 24 horas, que medimos em milímetros;

6 - pêso $P_{1,20}$, em 120 horas;

7 - ascensão $h_{120}$, em 120 horas;

8 - pêso $A_{24}$, de água absorvida em 24 horas,

$$
A_{24}=P_{24}-P \text {; }
$$

9 - pêso $A_{120}$, de água absorvida em 120 horas,

$$
\mathbf{A}_{120}=\mathbf{P}_{120}-\mathrm{P} \text {; }
$$

10 - gramas de TF S A molhada em 24 horas,

$$
\frac{\mathrm{p}}{900} \cdot \mathrm{h}_{24} \text {; }
$$

11 - gramas de água absorvida percentualmente em pêso de T F SA em 24 horas,

$$
\frac{100 \cdot \frac{A_{24}}{p}}{\frac{p}{900} \cdot h_{24}} ;
$$

12 - gramas de TF S A molhada em 120 horas,

$$
\frac{\mathrm{p}}{900} \cdot \mathrm{h}_{120}
$$

13 - gramas de água absorvida percentualmente em pêso de T F SA em 120 horas,

$$
\frac{100 \cdot A_{120}}{\frac{p}{900} \cdot h_{120}}
$$




\section{DADOS DEFINITIVOS QUE REGISTAMOS}

1 -. Ascensão capilar final, em milímetros,

$$
\mathrm{hT}=\frac{4 \mathrm{~h}_{24} \mathrm{~h}_{120}}{5 \mathrm{~h}_{24}-\mathrm{h}_{120}}
$$

2 - velocidade máxima de ascensão capilar, em $\mathrm{mm} / \mathrm{hora}$,

$$
V_{h}=\frac{h_{24} h_{120}}{30\left(h_{120}-h_{24}\right)}
$$

3 - altura máxima de água absorvida, em milímetros,

$$
\mathrm{H} T=\frac{4 \mathrm{H}_{21} \cdot \mathrm{H}_{120}}{5 \mathrm{H}_{24}-\mathrm{H}_{120}}
$$

onde, $\mathrm{H}_{24}$ é a altura, em milímetros da camada de água que o solo absorve em 24 horas, e vale $3,183 A_{24}$, sendo que $H_{120}$ tem valor análogo ;

4 - velocidade máxima de absorção de água, em $\mathrm{mm} / \mathrm{hora}$,

$$
\mathrm{VH}=\frac{\mathrm{H}_{24} \cdot \mathrm{H}_{120}}{30\left(\mathrm{H}_{120}-\mathrm{H}_{24}\right)}
$$

j - água capilar máxima, ou, capacidade máxima de retenção de água,

A $\%$ em pêso de TFSA $=\frac{100 A_{120}}{\frac{p}{900} \cdot h_{120}}$.

Êste dado, como se vê, nós o identificamos com o número de gramas de água absorvida percentualmente em TF S A em 120 horas.

\section{OBSERVAÇÕES FINAIS}

A tabela 2 fornece alguns dados de água referentes aos grandes tipos de solo do Estado de São Paulo.

Depois da tabela 5 estampamos um diagrama volumétrico físico, que esclarece como registamos, finalmente, por cento em volume, os seguintes dados :

1. ${ }^{\circ} \mathrm{Hy}$, U.Eq. e A que devem ser lidos a partir do zero até a linha limite à direita;

2..$^{\circ}$ Argila, areia fina mais limo, areia grossa, seixos, pedras e ar, cujas respectivas percentagens são dadas pelo segmento de reta determinado no lado superior do retângulo pelas linhas limites.

O diagrama apresentado é de um perfil típico de terra roxa legítinä, procedente da Estação Experimental de Ribeirão Preto. E um perfil de solo autoctone, retirado em local de derrubada recente.

Acompanha êste trabalho um mapa do Estado de São Paulo que exibe os grandes tipos de solo do Estado. Chamamos de grandes tipos de solo do Estado, os vários solos, originários das diferentes formações geológicas, 
reunidas, às vêzes, segundo certos critérios que passamos a esclarecer : reunimos as formações Tatuí e Glacial sob a denominação de grande tipo Glacial, que se apresenta muito variável, e até o momento nos foi impossivel, por falta de mapas litológicos, locar satisfatòriamente as suas variaçóes.

$\mathrm{Na}$ legenda da geologia aparece a formação geológica Caiuá, citada em trabalhos anteriores da nossa secção como Bauru inferior, que, em virtude de sua semelhança com a formação geológica Triássica, Arenito Botucatu, foi reunida a esta, formando o grande tipo de solo Arenito Botucatu.

Futuramente, quando fôr possivel precisar as regiões arenosas do grande tipo Glacial, elas serão inclúdas no grande tipo Arenito Botucatu, tal é a semelhança física e química dêsses tipos de solo.

Estes arranjos têm por fim facilitar a visão de conjunto dos problemas de física do solo do Estado.

A região de Franca, Pedregulho etc. aparece como formação Bauru, por têrmos considerado a classificação da comissão geológica, que é citada ao lado do mapa. E preciso êste esclarecimento, porque há muita divergência entre os geólogos quanto à geologia dessa região.

\section{T A B E L A 1}

\begin{tabular}{|c|c|c|}
\hline \multirow{2}{*}{ AMOSTRAS DE SOLO } & \multicolumn{2}{|c|}{ U.mu. $\%$ em pêso de TFSA } \\
\hline & Observada & Calculada \\
\hline$\ldots \ldots \ldots \ldots \ldots \ldots \ldots \ldots \ldots$ & 13,91 & 13,81 \\
\hline $1694 \mathrm{~T}$ & 18,50 & 17,82 \\
\hline $1695 \mathrm{~T}$ & 16,95 & 16,18 \\
\hline Faz. Mato Dentro $1 \ldots$ & 12,97 & 12,84 \\
\hline Faz. Mato Dentro 2. & 9,44 & 9,97 \\
\hline Faz. Mato Dentro 3 . & 15,51 & 15,77 \\
\hline Perfil 499 a $\ldots \ldots \ldots \ldots \ldots \ldots \ldots \ldots \ldots$ & 15,40 & 16,73 \\
\hline Perfil 500 a $\ldots \ldots \ldots \ldots$ & 14,98 & 15,98 \\
\hline Perfil 501 a $\ldots \ldots \ldots \ldots \ldots \ldots \ldots \ldots \ldots$ & 12,13 & 12,10 \\
\hline Av. 512 a . & 4,10 & 4,30 \\
\hline Av. 512 b $\ldots$ & 6,40 & 6,50 \\
\hline Av. 512 a $\ldots \ldots \ldots \ldots \ldots$ & 4,00 & 4,20 \\
\hline Av. 512 b & 7,60 & 7,20 \\
\hline
\end{tabular}

Foram utilizadas as mais diferentes possíveis amostras de solo.

A U.mu. observada é fornecida pela Seçã̃o de Fisiologia Vegetal do Instituto Agronômico de Campinas (6), e a U.mu. calculada é obtida com a fórmula U.mu. $\%=0,68$ U.Eq. $\%$. 
E preciso uma média de 20 dias para obter diretamente a umidade de murchamento de uma amostra de solo, ao passo que podemos determinar 30 U.Eq. em um só dia.

\section{TA B E L 2}

\begin{tabular}{|c|c|c|c|c|}
\hline \multirow{2}{*}{$\begin{array}{l}\text { Os grandes tipos de solo } \\
\text { do Estado de São Paulo }\end{array}$} & \multicolumn{4}{|c|}{ Campo mais frequente de variação dos dados } \\
\hline & $\mathrm{W} . \%$ & $\mathrm{Hy} . \%$ & U.mu.\% & U.Eq. \% \\
\hline 1 - Arqueano............ & $1-3$ & $7-13$ & $10-17$ & $15-25$ \\
\hline 2 - Devoniano........... & $2-3$ & $7-11$ & $10-14$ & $15-20$ \\
\hline arenoso .. & $0,5-1$ & $2-4$ & $3-5$ & $5-8$ \\
\hline argiloso . & $2-3$ & $8-15$ & $10-17$ & $15-25$ \\
\hline $4-$ Corumbataí.......... & $2-4$ & $5-12$ & $10-17$ & $15-25$ \\
\hline 5 - Terra roxa legitima .... & $2-4$ & $14-18$ & $17-21$ & $25-30$ \\
\hline 6 - Arenito Botucatu ..... & $0,2-1$ & $1,5-3$ & $2-4$ & $3-6$ \\
\hline 7 - Terra roxa misturada... & $1-3$ & $6-12$ & $7-14$ & $10-20$ \\
\hline 8 - Arenito Bauru ...... & $0,4-1,2$ & $2-5$ & $4-5$ & $6-8$ \\
\hline 9 - Terciário ........... & $1,5-2$ & $6-10$ & $8-14$ & $12-20$ \\
\hline 10 - Baixadas .......... & m. $v$. & m. v. & m. v. & m. v. \\
\hline
\end{tabular}

m. v. significa muito variável.

Fizemos 3120 determinações de U.Eq. e 1560 determinações de W e Hy. A U.mu. é calculada, vale 0,68 U.Eq.

Os dados se referem ao solo arável, $0-40 \mathrm{~cm}$.

T A B E L A 3

\begin{tabular}{|c|c|c|}
\hline \multirow{2}{*}{ HORAS NA ESTUFA } & \multicolumn{2}{|c|}{ Hy \% pêso } \\
\hline & Perfil 257 a & Perfil 257 b \\
\hline 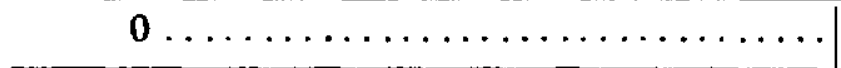 & 12,8 & 11,3 \\
\hline $3 \ldots \ldots \ldots \ldots \ldots \ldots \ldots$ & 13,3 & 10,9 \\
\hline $6 \ldots \ldots \ldots \ldots \ldots \ldots \ldots \ldots \ldots$ & 13,3 & 11,1 \\
\hline $18 \ldots$ & 12,9 & 11,3 \\
\hline mais de 48 & 13,1 & 11,1 \\
\hline
\end{tabular}

Vemos que o Hy do perfil 257 a - b não se alterou, fazendo variar o tempo de secagem na estufa, antes da exposição no dessecador com $\mathrm{H}_{2} \mathrm{SO}_{4}$ 
O perfil 257 é da Estação Experimental de Ribeirão Preto, onde a terra é roxa legítima, rica em colóides (gels de $\mathrm{SiO}_{2} . \mathrm{n} \mathrm{H}_{2} \mathrm{O}, \mathrm{Al}_{2} \mathrm{O}_{8} . \mathbf{n ~}_{2} \mathrm{O}$, $\mathrm{F}_{2} \mathrm{O}_{3}$. $\mathrm{n}_{2} \mathrm{O}$, principalmente) e que, por isso mesmo, poderia exibir variações na higroscopicidade, em virtude dos diferentes tempos de secagem antes da determinação.

Esta classe de experiências nos autoriza a obter ao mesmo tempo o $\mathrm{W}$ e o $\mathrm{Hy}$, sem inconvenientes; levando os 20 gramas de $\mathrm{T}$ F S A à estufa antes da exposição no dessecador.

T A B L A

\begin{tabular}{|c|c|c|}
\hline P E R F I L. & $\begin{array}{l}\text { Trocáveis em M E } \\
\text { por } 100 \mathrm{~g} \text { de } \\
\text { T F S E }\end{array}$ & Hy \% pêso \\
\hline 400 a $\ldots \ldots \ldots \ldots \ldots \ldots \ldots \ldots \ldots \ldots$ & 35,050 & 15,7 \\
\hline b.......... & 11,902 & 17,1 \\
\hline$c \ldots \ldots \ldots \ldots \ldots$ & 9,301 & 16,1 \\
\hline $\mathrm{d} \ldots \ldots$. & 7,205 & 15,4 \\
\hline $\mathrm{e} \ldots \ldots \ldots \ldots \ldots \ldots \ldots \ldots \ldots$ & 5,167 & 17,6 \\
\hline 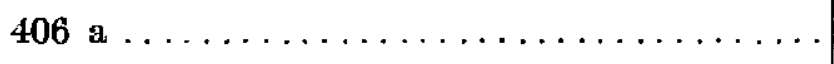 & 27,060 & 16,4 \\
\hline b. & 9,272 & 18,0 \\
\hline c & 6,793 & 17,1 \\
\hline $\mathrm{d} \ldots .$. & 5,763 & 17,1 \\
\hline$\ldots \ldots \ldots \ldots \ldots \ldots \ldots$ & 4,413 & 18,2 \\
\hline
\end{tabular}

TA B E L A 5

AMOSTRA DE SOLO

Hy $\%$ pêso

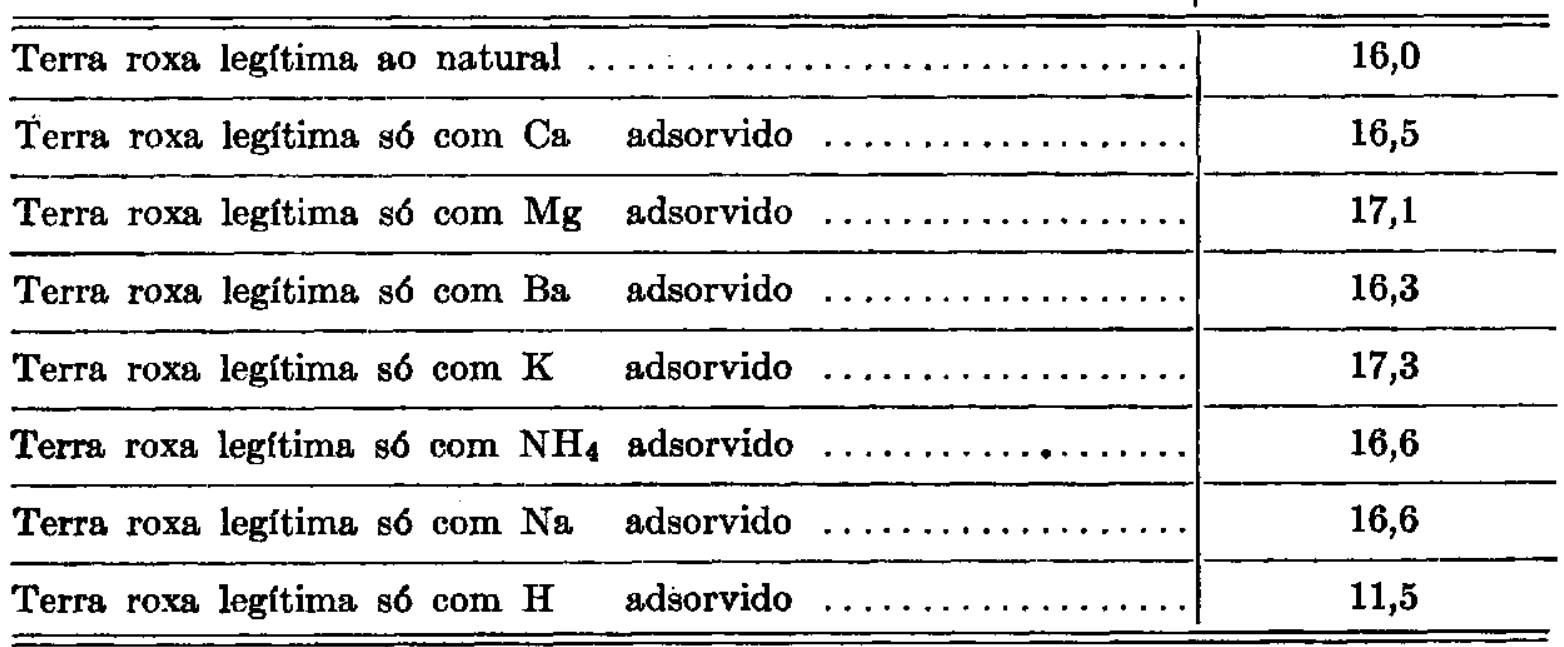


Vageler e Alten (11, 12) estabeleceram as seguintes fórmulas para o cálculo do $\mathrm{Hy}$ de solos ácidos em função dos iônios permutáveis :

$$
\mathrm{Hy}=0,44\left[\mathrm{~T}-0,5\left(\frac{\mathrm{Ca}}{2}+\frac{\mathrm{Mg}}{2}\right)-\frac{2}{3} \frac{\mathrm{Al}}{3}\right]
$$

Para solos não ácidos, os autores acima preconizam, segundo Eckstein. (7) a fórmula :

$$
\mathrm{Hy}=0,44\left(\mathrm{~T}-\frac{\frac{\mathrm{Ca}}{2} \cdot \frac{\mathrm{Mg}}{2}}{2}\right)
$$

As tabelas 4 e 5 mostram que estas fórmulas não se aplicam à nossa terra roxa legítima. De fato, a única variação importante do $\mathrm{Hy}$ se constata na terra roxa legítima que possui sòmente o $\mathbf{H}$ - catiônio adsorvido.

\section{RESUMO}

A retenção de água pelo solo se deve exclusivamente a fôrças capilares. Tôda divisão da água do solo é convencional.

Quando se utiliza a equação $\mathrm{y}=\frac{\mathrm{x} T}{\mathrm{x}+\mathrm{q} T}$ no estudo de processos que têndem para um valor final, a velocidade do fenômeno é dada por $\frac{l}{q}$.

E possível calcular para os solos do Estado de São Paulo a Umidade de murchamento por meio da Umidade equivalente.

$$
\text { U. } \mathrm{mu} .=0,68 \text { U.Eq. }
$$

Não se pode, em geral, aplicar com sucesso as fórmulas de Vageler e Alten para o cálculo do Hy em função dos trocáveis.

$\mathrm{O}$ Hy do solo não se altera fazendo variar o tempo de secagem na estufa $\left(105^{\circ}-110^{\circ} \mathrm{C}\right)$ antes da determinação.

Os valores máximos dos dados referentes à água do solo foram encontrados na terra roxa legítima e os mínimos no Arenito Botucatu.

\section{S U M M A R Y}

The retention of moisture by soil is conditioned exclusively by eapillary forces.

Any division of soil water is merely conventional. Using the formula $y=\frac{x T}{x+q T}$ to compute the final value of a process, it is important to note that the velocity of the phenomenon is given by $\frac{1}{q}$. For the major soil types of the State of São Paulo it is possible to calculate the wilting point by means of the moisture equivalent using the formula Wp. $=0,68 \mathrm{M} . \mathrm{Eq}$.

In general, the formulae of Vageler and Alten for computing hygroscopicity by means of exchangeable-ions are inadequate. 
Different periods of exposure of soils to temperatures of $105^{\circ}-110^{\circ} \mathrm{C}$. before determinations are made do not exert a pronounced influence on hygroscopicity.

The highest values for water-holding capacity were obtained in the terra roxa legitima and the lowest in the Botucatu sandstone.

\section{LITERATURA CITADA}

1. Albareda, J. M. Em El Suelo, pág. 1-485, 1." ed., Madrid, Sociedad Anonima Española de Traductores y Autores, 1940.

2. Briggs, L. J. e J. W. Me Lane. The moisture equivalent of soils. U. S. Dept. Agr. Bur. Soils. Bul. 45 : 1-23. 1907.

3. Briggs, L. J. e J. W. Mc Lane. Moisture equivalent determinations and their application. Proc. Am. Soc. Agron. 2: 38-147. 1910.

4. Briggs, L. J. e H. L. Shantz. The Wilting coefficient for different plants and its indirect determination. U. S. Dept. Agric. Bul. 230:1-25. 1912.

5. Camargo, T. e P. Vageler. Anályses de Solos, I - Analyse Physica, Bol. Tec. do Instituto Agronômico de Campinas 24 : 1-78. 1936.

6. Franco, C. M. e H. C. Mendes. Água inativa de alguns tipos de solo do Estado de São Paulo. Bragantia. 7 : 129-132. 1947.

7. Eckstein, O. Em Arbeiten Uber Kalidüngung, pág. 1-477, 1." ed., Berlin, Verlagsgesellschaft für Ackerbau M. B. H., 1935.

8. Keen, B. A. Em The Physical Properties of the Soil, pág. 1-380, 1.ª ed., London, New York, Toronto. Longmans, Green and Co., 1931.

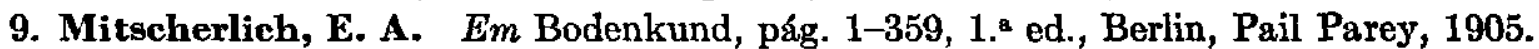

10. Vageler, P. $E m$ Der Kationen-und Wasserhauschalt des Mineralbodens, pág. 1-316, 1." ed., Berlin, Julius Springer, 1932.

11. Vageler, P. e F. Alten. Bōden des Nil und Gash IV. Zeitschrift f. Pflanzenernährung, Düngung und Bodenkunde 22: 1-77. 1931.

12. Vageler, P. e F. Alten. Böden des Nil und Gash V e VI. Zeitsch rift f. Pflanzenernährung, Düngung und Bodenkunde 23 : 1-189. 1932.

13. Walter, H. Em Die Hydratur der Pflanze, pág. 1-164, 1.a ed., Jena, Gustav Fischer, 1931. 


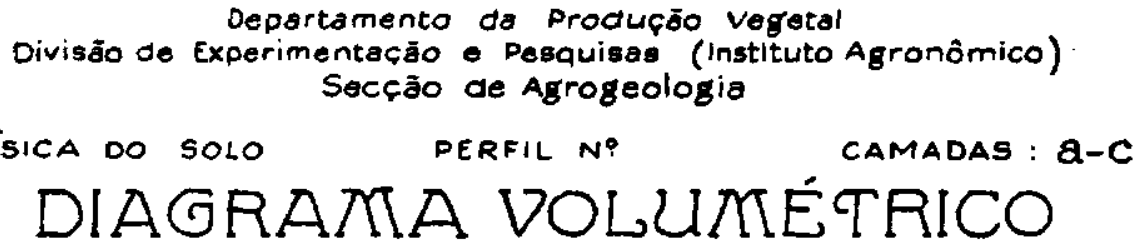

ESTADO: SäO PaUlo

MUNICÍPIO: Rideirão Preto

LOCALIOADE: EST. EXDERimental

ALTITUDE: $701.2 \mathrm{~m}$

FORMACĀO GEOLÓGICA: Botucatu

ROCHA MATER: DiBbasio

VEGETAGÃo: Cofezal

TIPO DO SOLO: Terra roxa legitima

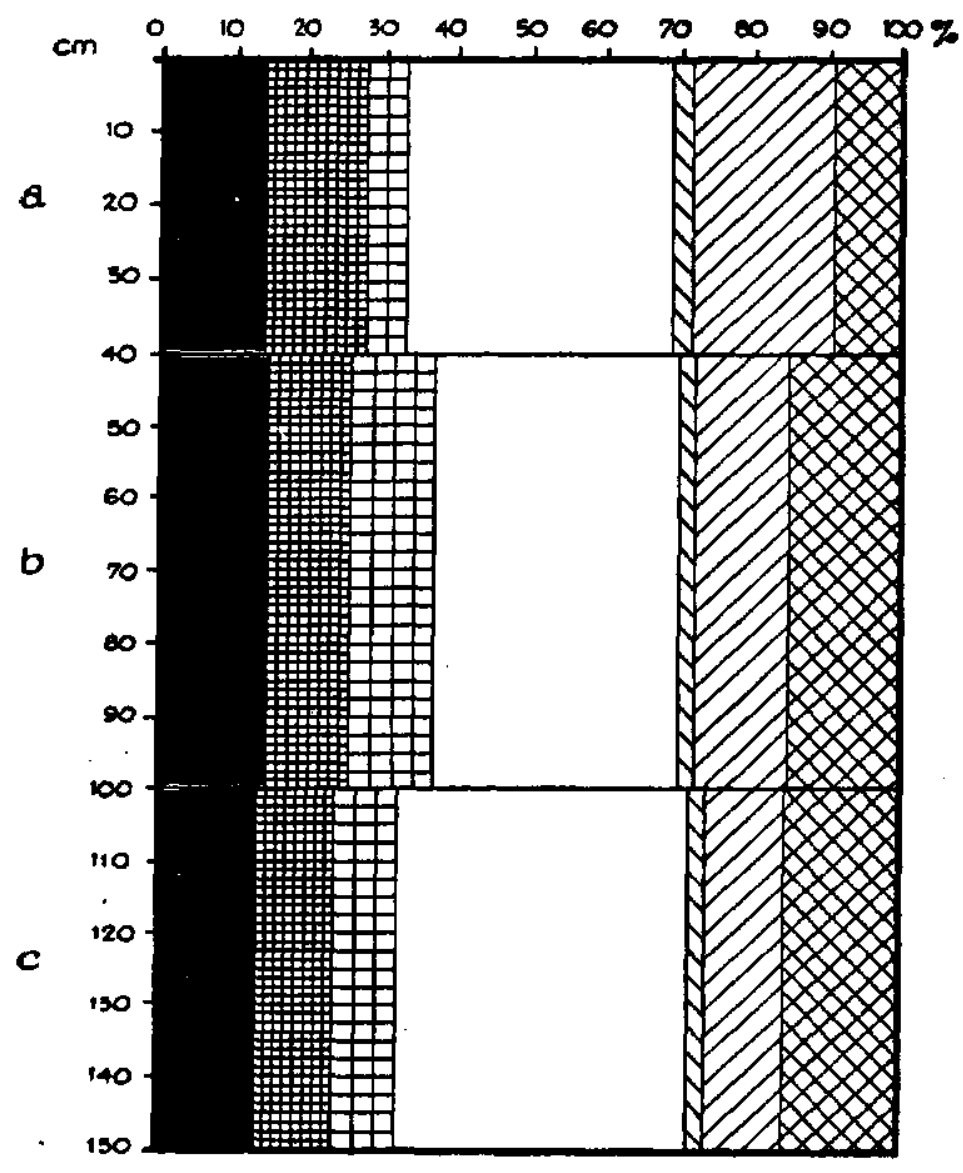

Hy. nat. $\quad$ Q

umidade eq.

$\triangle$ Areis $\mathrm{gr}$.

UtA Agua capilar max.

8 areia $f .+l i m o$

ar

$\triangle 8$ argila 

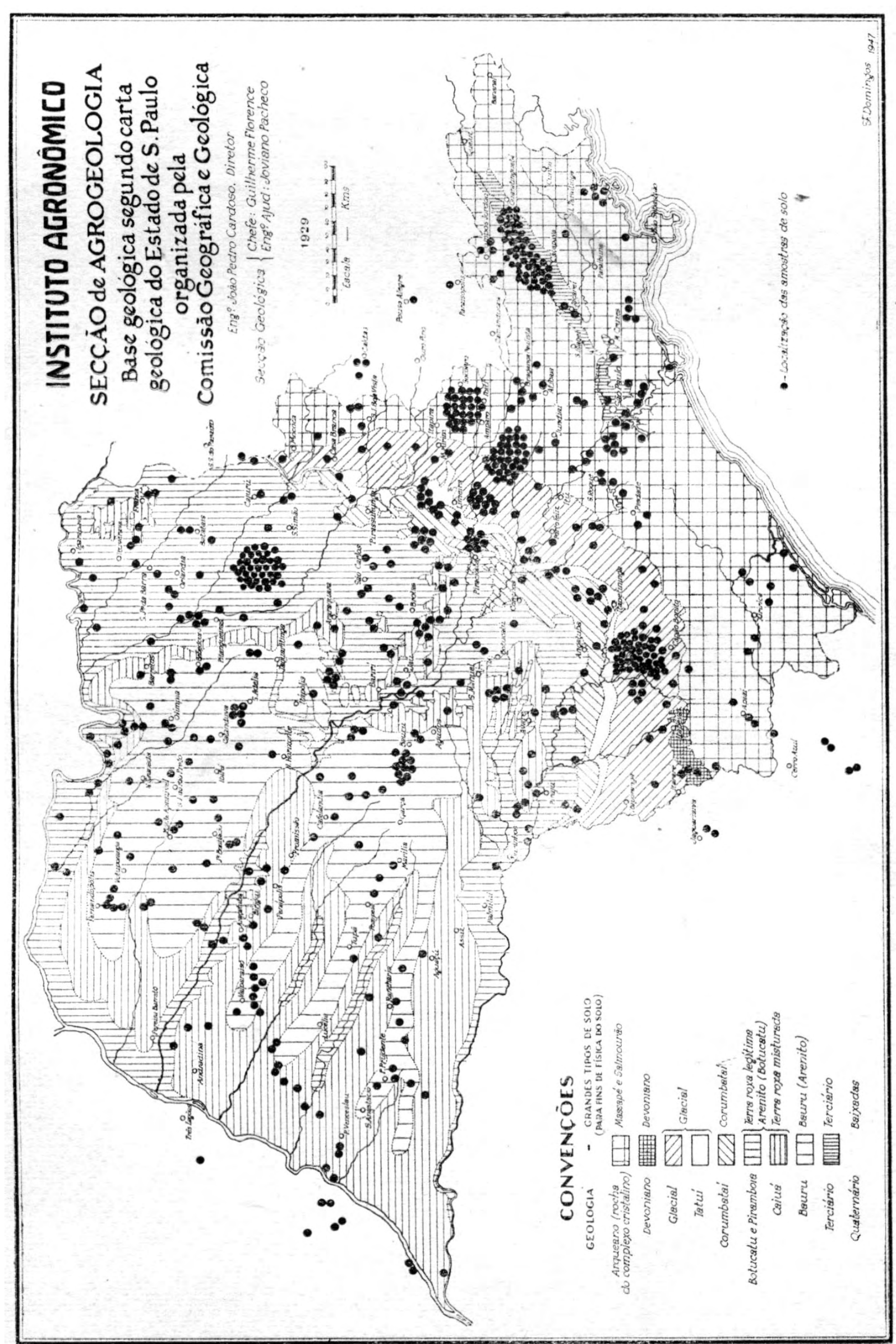